\title{
Follow-up study of juvenile chronic polyarthritis with particular reference to histocompatibility antigen W.27
}

\author{
JOHN EDMONDS, ROBERT I. MORRIS, ALLAN L. METZGER, \\ RODNEY BLUESTONE, PAUL I. TERASAKI, BARBARA ANSELL,
} AND E. G. L. BYWATERS

From the M.R.C. Rheumatism Unit, Canadian Red Cross Memorial Hospital, Taplow, Berkshire; the Department of Medicine and Surgery, University of California, Los Angeles School of Medicine; and the Medical and Research Services, Wadsworth Hospital Centre, Los Angeles, California, U.S.A.

The HL-A antigen W.27 has been found in 88 to $96 \%$ of patients with ankylosing spondylitis (Brewerton, Caffrey, Hart, James, Nicholls, and Sturrock, 1973a; Caffrey and James, 1973; Schlosstein, Terasaki, Bluestone, and Pearson, 1973). More recently a high frequency of W.27 has been reported in Reiter's syndrome (Brewerton, Caffrey, Nicholls, Walters, Oates, and James, 1973c), acute anterior uveitis (Brewerton, Caffrey, Nicholls, Walters, and James, 1973b), and Yersinia arthritis (Aho, Ahvonen, Lassus, Sievers, and Tiilikainen, 1973). In a control Caucasian population, the frequency of W.27 is 4 to $8 \%$ (Brewerton and others, 1973a; Schlosstein and others, 1973).

The long-term follow-up of juvenile chronic polyarthritis has shown that a small proportion of patients presenting with peripheral arthritis may ultimately develop definite ankylosing spondylitis (Ansell, 1969; Chalmers, 1971), and others may show radiological sacroiliitis of ankylosing spondylitis type (Bywaters and Ansell, 1965). Family studies of patients with juvenile chronic polyarthritis have shown an increased incidence of ankylosing spondylitis in male relatives and of seronegative chronic polyarthritis in female relatives (Ansell, Bywaters, and Lawrence, 1962), and of sacroiliitis in male relatives aged 15 and over and in female relatives aged 45 and over (Ansell, Bywaters, and Lawrence, 1968).

We decided to tissue type a small group of patients with juvenile chronic polyarthritis, who had been followed up for many years so that their pattern of disease had become established.

\section{Patients and methods}

HL-A antigens were identified by the microdroplet lymphocyte cytotoxicity test (Mittal, Mickey, Singal, and Terasaki, 1968) in 46 patients attending our follow-up clinics. 44 of them had fulfilled our original criteria for definite juvenile chronic polyarthritis when first seen
(Ansell and Bywaters, 1959), and a further two had originally been classed as probable (Ansell and Bywaters, 1962). In addition to a full clinical examination and determination of rheumatoid factor (Rose Waaler and Tube Latex), a plain supine $x$-ray of the pelvis was taken in all patients if none was available within the previous year. These pelvic $x$-rays were read before the results of the tissue typing were known. All patients were Caucasian; none had developed bowel disease or psoriasis during the course of follow-up. They were selected to give adequate numbers in the following four groups.

\section{Group 1 Ankylosing spondylitis}

This comprised seven patients who had originally presented with juvenile chronic polyarthritis, six definite and one probable, and subsequently developed definite ankylosing spondylitis. Six were men and one a woman, their present ages ranging from 25 to 37 years (average 31.2 yrs) with a disease duration of from 15 to 23 years (average 19.9 yrs). All had clinical features of ankylosing spondylitis, sacroiliitis and typical radiological change in the spine; three had had acute iritis on one or more occasions. All were seronegative.

\section{Group 2 Sacroiliitis of ankylosing spondylitis type} There were eight males, seven with definite and one with probable (Figure) juvenile chronic polyarthritis originally, who later developed radiological changes of sacroiliitis of ankylosing spondylitis type; none had clinical or radiological evidence of spinal abnormality; all were seronegative. Four had had acute iritis on one or more occasions. Their present ages ranged from 15 to 19 years (average 16.9 yrs) and their disease duration was from 2 to 11 years (average $7 \mathrm{yrs}$ ).

\section{Group 3 Seronegative juvenile chronic polyarthritis}

This consisted of twenty patients who had no radiological evidence of sacroiliitis of ankylosing spondylitis type. There were twelve females and eight males in the group; all but two had widespread arthritis, all had residua, and in six the disease was still active; all were seronegative. 
Their present ages ranged from 14 to 42 years (average 21.1 yrs) with a disease duration of between 11 and 32 years (average $21.4 \mathrm{yrs}$ ). One patient in these twenty had had chronic uveitis.
Group 4 'Juvenile rheumatoid arthritis'

This group comprised eleven patients who had been persistently seropositive with symmetrical joint involvement, particularly of the MCP, PIP, and MTP joints; the

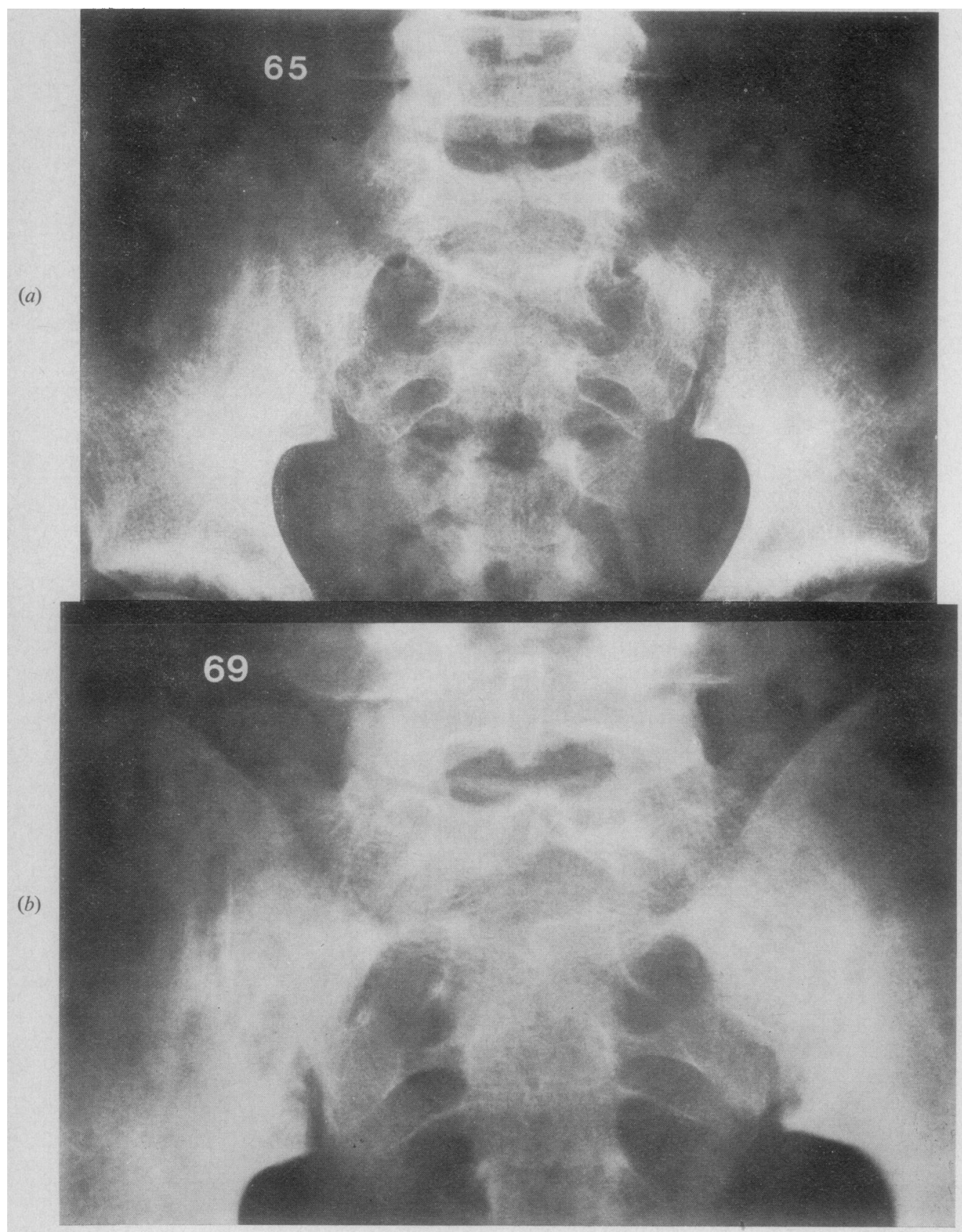

FIGURE Male with probable juvenile chronic polyarthritis. When aged 9 he developed arthritis in the knees which settled in 3 months. 2 years later, onset of persistent arthritis of the left ankle associated with acute iridocyclitis, which has recurred on two occasions. X-rays of the pelvis at age 11 appeared normal (a), but by the age of 15 years (b) sacroiliitis was present. HL-A27 present. 
development of elbow nodules and early erosive changes suggested a pattern of illness like adult rheumatoid arthritis. There were eight females and three males whose present ages ranged from 19 to 41 years (average 31.4 yrs) and whose disease duration was from 9 to 29 years (average $19.7 \mathrm{yrs})$. All had active disease, and none had radiological changes of sacroiliitis. None had uveitis.

\section{Results}

The results for the different groups are shown in the Table. Of group 1 patients, six of the seven had W.27; among those positive, five were male and one female. All of the eight males in group 2 had W.27. In group 3, i.e. juvenile chronic polyarthritis without sacroiliac changes of ankylosing spondylitis type, four of the twenty had W.27; two were male and two were female. None of the eleven patients with juvenile rheumatoid arthritis in group 4 had W.27.

\section{Discussion}

Regular long-term surveillance of over 25 years of children suffering from juvenile chronic polyarthritis has shown that a small proportion develop ankylosing spondylitis; in our 15-year follow-up of 244 patients presenting with juvenile chronic polyarthritis, nineteen had progressed to ankylosing spondylitis. The presentation of ankylosing spondylitis in childhood is seldom typical, especially in those starting before puberty; back pain or limitation is usually absent and even radiological signs of sacroiliitis may be deferred for several years; presentation at this early age is much more likely to be that of a peripheral arthropathy.

Radiological changes in the sacroiliac joint occur in about $20 \%$ of children with juvenile chronic polyarthritis, but several different types may be recognized. One type is related to immobilization, bed rest, and/or hip involvement which often go together, and is characterized by fusion without erosion and often without sclerosis. A second type shows minor erosive changes, often unilateral and without sclerosis, while the third type is a sacroiliitis similar to that seen in ankylosing spondylitis (Chalmers, 1971) (Figure).
Some, but not all, of this last type progress to clinical ankylosing spondylitis (Ansell, 1969). A small proportion of cases develop psoriasis; and much less commonly, bowel disorders such as ulcerative colitis or regional enteritis may develop. These have tended to appear in cases which have not fulfilled our definite criteria and which had been originally classed as 'probable' Still's disease (Ansell and Bywaters, 1962).

The frequency of W.27 in a control Caucasion population is reported as between 4 to $8 \%$ (Brewerton and others, 1973a; Schlosstein and others, 1973). Our results for the whole group show 18 of the 46 patients $(39 \%)$ positive for W.27, but it should be noted that this cannot be regarded as representative of the general incidence of W.27 in juvenile chronic polyarthritis as our group has been selected with a bias towards those cases who had developed sacroiliitis. We felt it was important in an initial study to look at well-defined subgroups, because in the early cases it is difficult to be certain of the pattern the disease will follow. Although the numbers are small and not of statistical significance, it is of interest that in the group of juvenile chronic polyarthritis followed for many years without developing sacroiliac joint changes, the incidence of W.27 was higher than expected, being four out of twenty $(20 \%)$. Since two of these were male and two female, it appears that the presence of this antigen is not always expressed as sacroiliitis when present in males with juvenile chronic polyarthritis. This is in accord with the findings in a group of 26 American patients with juvenile arthritis (Rachelesfsky, Terasaki, Katz, and Stiehm, 1974) where the overall incidence was $42 \%$.

In our group of patients with juvenile rheumatoid arthritis, i.e. seropositive with a pattern of illness like adult rheumatoid arthritis, the HL-A antigen distribution was not significantly different from the control group, and this supports previous studies in adult rheumatoid arthritis (Lies, Messner, and Troup, 1972; Seignalet, Clot, Sany, and Serre, 1972).

In our study there was a striking association between W.27 and sacroiliitis. In view of the recent report of W.27 in acute uveitis (Brewerton and

Table $H L-A$ tissue typing in juvenile chronic polyarthritis

\begin{tabular}{|c|c|c|c|c|c|c|}
\hline Groups & $\begin{array}{l}\text { Total } \\
\text { no. }\end{array}$ & $\begin{array}{l}H L-A 27 \\
\text { positive }\end{array}$ & $\begin{array}{l}\text { No. of } \\
\text { males }\end{array}$ & $\begin{array}{l}H L-A 27 \\
\text { positive }\end{array}$ & $\begin{array}{l}\text { No. of } \\
\text { females }\end{array}$ & $\begin{array}{l}H L-A 27 \\
\text { positive }\end{array}$ \\
\hline JCP progressing to AS & 7 & 6 & 6 & 5 & 1 & 1 \\
\hline JCP with sacroiliitis & 8 & 8 & 8 & 8 & 0 & 0 \\
\hline JCP without sacroiliitis & 20 & 4 & 8 & 2 & 12 & 2 \\
\hline JRA & 11 & 0 & 3 & 0 & 8 & 0 \\
\hline Total & 46 & 18 & 25 & 15 & 21 & 3 \\
\hline
\end{tabular}


others, 1973b), it is also noteworthy that the incidence of acute iritis was seven out of the fifteen in groups 1 and 2 with sacroiliitis.

The high frequency of W.27 in these patients suggests that there is a small subgroup within the main group of children suffering from seronegative polyarthritis in which there is a disorder more closely related genetically to ankylosing spondylitis. Although W.27 cannot be used as a marker of sacroiliitis in juvenile chronic polyarthritis, its detection, particularly in teenaged boys, should alert the clinician to the possibility of spondylitis and the necessity to check for sacroiliac $x$-ray changes, costo-vertebral involvement, and uveitis. The eventual significance of W.27 in the heterogeneous group of arthropathies presenting as juvenile chronic polyarthritis awaits a further long-term follow-up.

\section{Summary}

As the long-term follow-up of children with chronic polyarthritis has suggested that this is not a homogeneous group, tissue typing was performed on 46 patients whose duration of disease was sufficiently long for the pattern to have become established. Six of the seven patients whose illness had begun as juvenile chronic polyarthritis and who had progressed to ankylosing spondylitis had W.27, as did eight patients with sacroiliitis of ankylosing type. Acute iritis had occurred only in those with sacroiliitis; fourteen of the fifteen with sacroiliitis were male. Four of twenty patients with juvenile chronic polyarthritis without sacroiliitis also had W.27. By contrast, none of the eleven patients who were seropositive and had a pattern of illness resembling adult rheumatoid arthritis were of this tissue type.

\section{References}

Aho, K., Ahvonen, P., Lassus, A., Sievers, K., And Tillikainen, A. (1973) Lancet, 2, 157 (HL-A antigen 27 and reactive arthritis)

Ansell, B. M. (1969) Proc. roy. Soc. Med., 62, 912 (Still's disease followed into adult life)

-, AND Bywaters, E. G. L. (1959) Bull. rheum. Dis., 9, 189 (Prognosis in Still's disease)

-, (1962) Ann. rheum. Dis., 21, 253 (Diagnosis of 'probable' Still's disease and its outcome)

- - - AND LAWRENCE, J. S. (1962) Ibid., 21, 243 (A family study in Still's disease)

_- _ -, 1 (1968) 'Family studies in Still's disease (juvenile RA)', in 'Population Studies of the Rheumatic Diseases', p. 229. Excerpta Medica, Amsterdam

Brewerton, D. A., Caffrey, M., Hart, F. D., James, D. C. O., Nicholls, A., and Sturrock, R. D. (1973a) Lancet, 1, 904 (Ankylosing spondylitis and HL-A 27)

- - Nicholls, A., WALTERs, D., AND JAMES, D. C. O. (1973b) Ibid., 2, 994 (Acute anterior uveitis and HL-A 27)

$\longrightarrow,-,-\longrightarrow$, OATES, J. K., AND JAMES, D. C. O. (1973c) Ibid., 2, 996 (Reiter's disease and HL-A 27)

BYwATER, E. G. L., AND ANSELl, B. M. (1965) Z. Rheumaforsch., 24, 122 (Sacroiliitis in juvenile chronic polyarthritis)

Caffrey, M. F. P., AND James, D. C. O. (1973) Nature, 242, 121 (Human lymphocyte antigen association in ankylosing spondylitis)

Chalmers, T. M. (1971) 'Ankylosing spondylitis in childhood and adolescence,' in 'Abstracts of the VII European Rheumatology Congress', 23.1

Lies, R. B., Messner, R. P., AND Troup, G. M. (1972) Arthr. and Rheum., 15, 524 (Histocompatibility antigens and rheumatoid arthritis)

Mrttal, K. K., Mickey, M. R., Singal, D. P., And Terasaki, P. I. (1968) Transplantation, 6, 913 (Serotyping for homotransplantation. XVIII. Refinement of microdroplet lymphocyte cytotoxicity test)

Rachelesfiky, G. S., Terasaki. P. I., Katz, R., AND StieHM, E. R. (1974) New Engl. J. Med., 290, 892 (Increased prevalence of $\mathrm{W} 27$ in juvenile rheumatoid arthritis)

Schlosstein, L., Terasaki, P. I., Bluestone, R., AND Pearson, C. M. (1973) Ibid., 288, 704 (High association of an HL-A antigen, W27, with ankylosing spondylitis)

Seignalet, J., Clot, J., SANY, J., AND SerRe, H. (1972) Vox. Sang., 23, 468 (HL-A antigens in rheumatoid arthritis) 